\title{
Size and print path effects on mechanical properties of material extrusion 3D printed plastics
}

\author{
Jia-Ruey $\mathrm{Ai}^{1} \cdot$ Bryan D. $\operatorname{Vogt}^{1}{ }^{10}$ \\ Received: 7 October 2021 / Accepted: 31 January 2022 / Published online: 24 February 2022 \\ (c) The Author(s), under exclusive licence to Springer Nature Switzerland AG 2022
}

\begin{abstract}
Print conditions for thermoplastics by filament-based material extrusion (MatEx) are commonly optimized to maximize the elastic modulus. However, these optimizations tend to ignore the impact of thermal history that depends on the specimen size and print path selection. Here, we investigate the effect of size print path (raster angle and build orientation) and print sequence on the mechanical properties of polycarbonate (PC) and polypropylene (PP). Examination of parallel and series printing of flat $(X Y)$ and stand-on $(Y Z)$ orientation of Type $\mathrm{V}$ specimens demonstrated that to observe statistical differences in the mechanical response that the interlayer time between printed roads should be approximately $5 \mathrm{~s}$ or less. The print time for a single layer in $\mathrm{XY}$ orientation is much longer than that for a single layer in $Y Z$ orientation, so print sequence only impacts the mechanical response in the $Y Z$ orientation. However, the specimen size and raster angle did influence the mechanical properties in $X Y$ orientation due to the differences in thermal history associated with intralayer time between adjacent roads. Moreover, all of these effects are significantly larger when printing PC than PP. These differences between PP and PC are mostly attributed to the mechanism of interface consolidation (crystallization vs. glass formation), which changes the requirements for a strong interface between roads (crystals vs. entanglements). These results illustrate how the print times dictated by the print path layout impact observed mechanical properties. This work also demonstrated that the options available in some standards developed for traditional manufacturing will change the quantitative results when applied to 3D printed parts.
\end{abstract}

Keywords Fused filament fabrication $\cdot$ Semicrystalline polymers $\cdot$ Polyolefin $\cdot$ Tensile properties

\section{Introduction}

Advances in machine design and processing have enabled 3D printing (3DP) of plastics by materials extrusion (MatEx) to transition from rapid prototyping to production (additive manufacturing, AM) [1-4]. Here we use the term MatEx to describe thermal filament-based 3D printing as prescribed by the revised ISO/ASTM2900 Additive ManufacturingGeneral Principles-Terminology. This printing modality has also been commonly referred as Fused Filament Fabrication (FFF) and by the Stratasys trademarked Fused Deposition Modeling (FDM). In addition to the potential advantages of 3DP for plastic manufacture associated with low initial investments and potential for mass customization, the quick turnaround from design to parts enables 3DP to

Bryan D. Vogt

bdv5051@psu.edu

1 Department of Chemical Engineering, The Pennsylvania State University, University Park, PA 16802, USA be a key production method to respond to crises as demonstrated with the COVID-19 pandemic [5, 6]. The increased variety of filaments available $[7,8]$, especially engineering plastics [9-11], has expanded potential applications for AM. However, one limitation $[12,13]$ to the widespread adaptation of MatEx for manufacturing is their inferior mechanical properties, which can strongly depend on the process [14-19]. Mechanical properties are path dependent and generally anisotropic that depends on build orientation [20]. The inferior mechanical properties have been attributed to incomplete filling (voids) and/or limitations with polymer diffusion to provide entanglements across interfaces between printed roads $[21,22]$. These attributes are controlled by details of the printing process and thus determining how to optimize the mechanical properties associated with MatEx 3D printing has been a significant thrust [23-25]. Additionally, significant efforts have been made to understand layer bonding in MatEx 3D printing due to its importance for the ultimate properties of the printed part [26-28]. 
As the effective weld time [29] for interface development between printed roads depends on the print details, the process parameters optimized for mechanical properties may be limited to the examined part shape. For products, the printed parts need to satisfy multiple characteristics through multiple-objective optimization, which tends to involve additional tradeoffs [30]. Recently, optimization routines have been applied to objects that are representative of products instead of mechanical test coupons [31,32], but direct comparisons were not drawn between these approaches. To understand print processes, instrumentation, typically measuring temperature, flow and pressure [21, 33, 34], provide process monitoring during the print that can assess potential issues to avoid expensive, post-print product monitoring like X-ray microcomputed tomography $(\mu \mathrm{CT})[35,36]$. Measurement of flow $[37,38]$ and temperature $[39,40]$ during MatEx 3D printing are particularly useful as these parameters correlate with the ultimate properties of the printed part. These inline monitoring data with appropriate models can predict the interlayer strength [21] or be applied to polymer weld theory [11]. The properties can be altered through post processing of 3D printed parts, which relaxes residual stresses [41, 42]. Despite these complexities, reporting of empirical optimization of print process parameters remains common [43-46], but the growing knowledge about the underlying principles that relate rate, temperature and pressure dependencies of the polymer flow during printing [21] to mechanical properties would suggest that the optimization should be object dependent. This object dependence is consistent with recent comparisons of standard test methods, ASTM D638-14 vs. UNE 116005 [47] and ASTM D638 vs. ASTEM D3039 [20], as well as specimen size with ASTM D638 [48]. The measured properties depend on standard selection, but physical insights into these observations have been limited.

From a molecular perspective, the bonding strength at the interface between adjacent roads is related to the local chain conformation that depends on the local thermal and flow history. The development of interfacial strength can be related to the welding of the printed roads, which should effectively be mechanistically similar to conventional welding where (1) surface contact, (2) surface rearrangement, (3) surface wetting, (4) chain diffusion, and (5) chain relaxation [49] define the weld quality. Typically, the welding quality relies on polymer diffusion across the interface to form bridging entanglements, which depends on the geometry of adjacent printed roads [50, 51] and the build (layer) orientation [52]. The overall print layout can affect the local thermal history, which determines the effective diffusion time [53]. Thus, printing multiple parts simultaneously can lead to changes in the mechanical properties as increased cooling between printed layers (interlayer time) leads to less effective polymer diffusion across interlayer to deteriorate mechanical properties [54]. The print path can significantly impact the mechanical properties of printed parts [55]. With the common optimization of print parameters for MatEx 3D printing based on objects that differ from the printed product, it is constructive to understand the origin and extent of sensitivity of mechanical properties to the object shape and the overall print path. Here, two standard ASTM D638 tensile bar sizes (Type IV and V) along with parallel and series printing of the specimens were examined for polycarbonate (PC) and polypropylene (PP). These plastics have been previously demonstrated for 3DP [7, 56-59], including as composites [60, 61], with PC exhibiting properties for potential engineering applications, while PP offers potential for a much lower cost. The elastic modulus was independent of these examined print characteristics, but the failure was dependent on the specimen size. Based on further investigation into raster angle and build orientation, these differences were attributed to the efficacy of the welding quality that depends on the time between both djacent printed roads, both interlayer and interlayer. If the time is sufficiently large between the printing of these adjacent roads, the mechanical response is effectively independent of specimen size and print sequence. The size effect on mechanical properties is significantly weaker for PP as the weld strength does not require large diffusion for entanglement as crystallization between adjacent roads strengthens the interface. These results illustrate that the sensitivity of the mechanical properties to details of the part size and shape, build orientation, and print sequence is related to the thermal history of adjacent printed roads.

\section{Experimental procedure}

Filaments of amorphous bisphenol-A polycarbonate (PC, Makrolon 3208, Covestro) were fabricated using a HAKKE single screw extruder (Rheomex 252p) and drawn by a takeup wheel to a diameter of $1.7 \pm 0.03 \mathrm{~mm}$. Additional details about the filament fabrication are included in the Supplementary Information (SI). Filaments of semi-crystalline polypropylene (PP) with diameter $1.75 \pm 0.05 \mathrm{~mm}$ were acquired from Verbatim, Inc. (P/N 55950). The commercial PP filament contained $0.1 \mathrm{wt} \%$ bis- 2 ethylhexyl phthalate (DEHP), $0.1 \mathrm{wt} \%$ benzyl butyl phthalate (BBP), $0.1 \mathrm{wt} \%$ dibutyl phthalate (DBP), and $0.1 \mathrm{wt} \%$ diisobutyl phthalate (DIBP), per specification from the manufacturer, to improve the flow properties.

ASTM D638 type IV and type V tensile bars were printed with a Roboze One +400 Xtreme printer These specimens differ in the width and length of the dogbone shape as illustrated in Fig. 1a, while a common thickness $(2 \mathrm{~mm})$ was used. The ASTM tensile specimen were printed using the following parameters: $0.25 \mathrm{~mm}$ layer height, $0.48 \mathrm{~mm}$ extrusion width, $20 \mathrm{~mm} / \mathrm{s}$ printing speed, $100 \%$ infill, and $0 / 90^{\circ}$ 


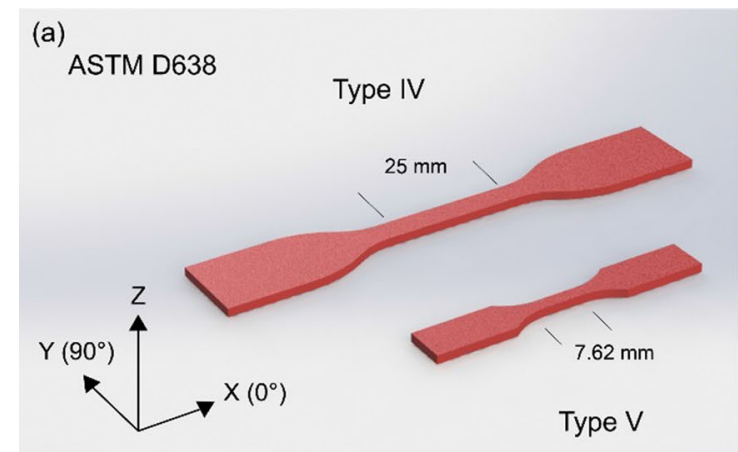

(b)
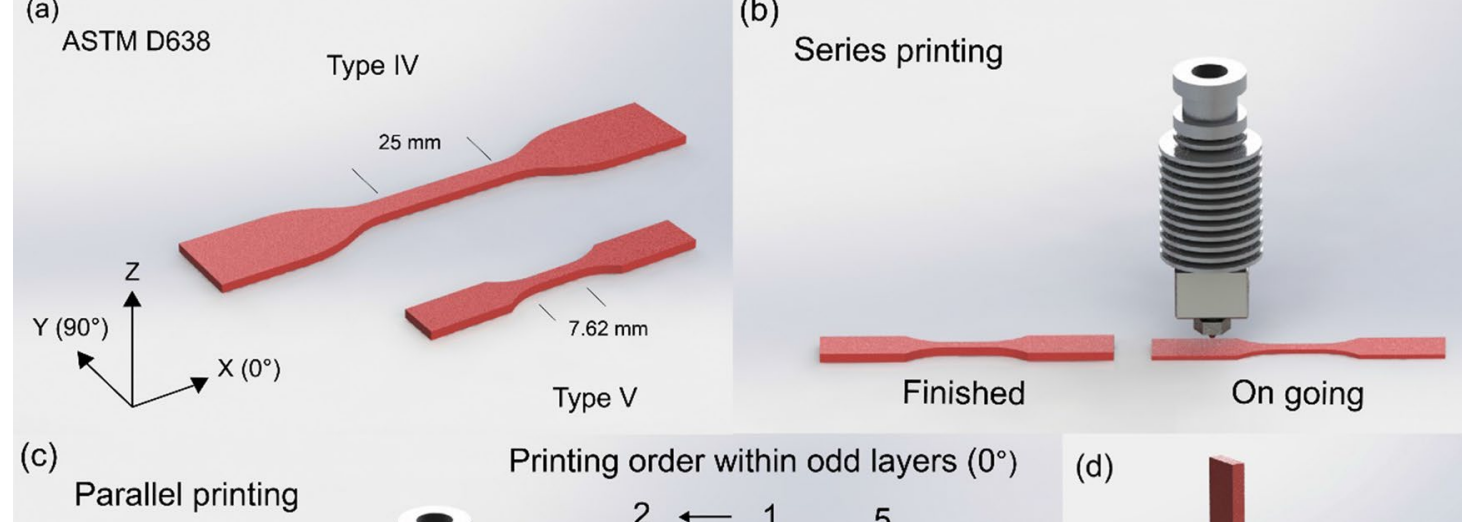

Printing order within odd layers $\left(0^{\circ}\right)$

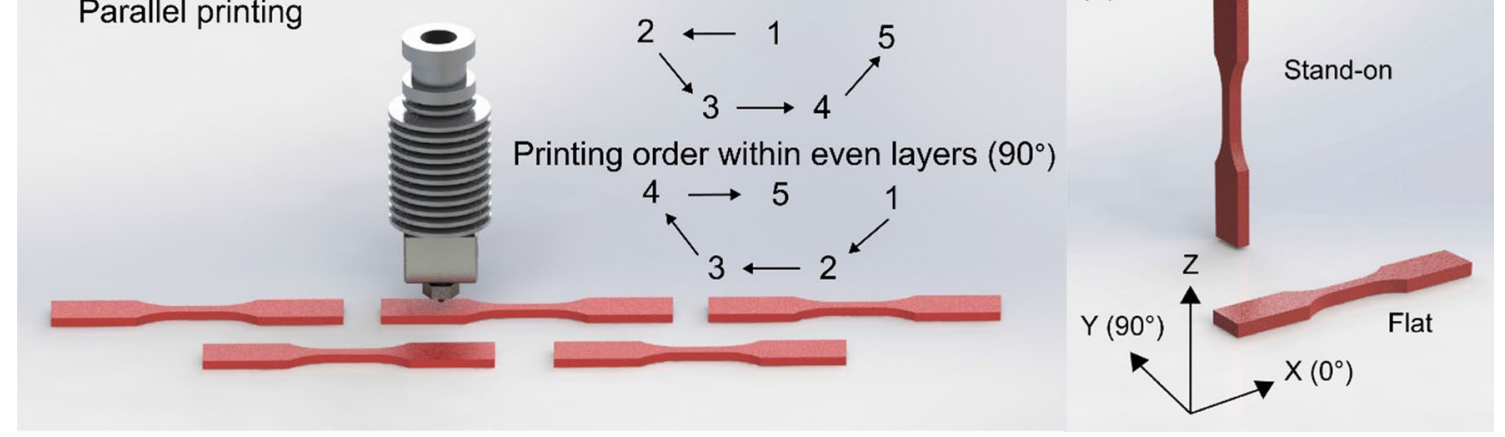

Fig. 1 a Illustration of the sizes of ASTM D638 type IV and type $\mathrm{V}$ tensile bars. b Schematic showing printing specimens in series. Each specimen is printed from start to finish before the next speci-

rectilinear infill pattern unless otherwise noted. Full explicit printing parameters are provided in the Supplementary Information (SI). These print conditions were determined from prior experience with PC [62] and the manufacturer guidance for PP along with the understanding of the thermal properties of these polymers as described in the SI. Five specimens were printed for each condition as suggested by ASTM D638. The use of five samples provides statistical significance to the properties reported and illustrates the reproducibility of the print under the conditions examined. Two distinct printing sequences (series and parallel) were used to understand the effect of thermal history. For series printing, all specimens have identical thermal histories, while for parallel printing, different interlayer thermal histories occur, especially for the first and the last specimen printed. Printing in series involved fully printing one specimen before moving to the next as shown in Fig. 1b, while printing in parallel involved printing five tensile bars simultaneously with the first layer for all five specimens completed before the 2nd layer began to print (Fig. 1c). Two build orientations, stand-on (YZ) and flat (XY) were used as shown schematically in Fig. 1d. men brings to print. c Printing in parallel where the nth layer for all 5 specimens completes before the $n+1$ layer begins. d Schematic for flat and stand-on print orientations

The tensile properties of the printed ASTM D638 specimens were measured using MTS 50kN loading frame system (Criterion Model 43) with $5 \mathrm{kN}$ load cell and video extensometer. The specimens were stretched at a constant displacement rate corresponding to an engineering strain rate of $1 \mathrm{~min}^{-1}$ until failure, which is consistent with the requirements of ASTM D638. All experiments were performed at room temperature. The data are reported in terms of engineering $\operatorname{strain}\left(\varepsilon=\frac{\Delta L}{L_{0}}\right)$ and engineering stress $\left(\sigma=\frac{F}{A_{0}}\right)$. The cross-sectional area $\left(A_{0}\right)$ in the gauge region prior to testing was determined using digital calipers. For the determination of the Young's Modulus, the true strain $\left(\varepsilon_{\text {true }}=\int \frac{\delta L}{L}\right)$ was determined from a video extensometer that measured the initial displacement, whereas engineering stress-strain are used for all other properties reported due to the limited field of view for the video extensometer. The tensile data were also used to determine the toughness from the area under the stress-strain curve prior to failure as $U_{\mathrm{T}}=\int_{0}^{\varepsilon_{\mathrm{f}}} \sigma \mathrm{d} \varepsilon$. The fracture surfaces were examined by scanning electron microscopy (SEM, Thermoscientific Apereo S) with an accelerating voltage of $1 \mathrm{kV}$ and a current of $25 \mathrm{pA}$. 


\section{Results and discussion}

The tensile properties of 3D printed polymers are commonly measured following standards, such as ASTM D638, which were developed for traditional polymer manufacture. As shown in Fig. 2a, the PC exhibits brittle failure when printed in a type IV dogbone at raster angles of $0^{\circ} / 90^{\circ}$. This is counter to injection molded PC, which exhibits ductile failure [63], but consistent with brittle fracture observed with other 3D printed PC dependent on build orientation and testing rate [57]. However, decreasing the specimen size to type $\mathrm{V}$ with the same print conditions leads to ductile failure as shown in Fig. 2b. This difference does not appear to be due to the interlayer thermal history as tensile behavior is similar for the type $\mathrm{V}$ printed in parallel as shown in Fig. 2c. This change from series to parallel alters the thermal
Table 1 Estimated printing time of each layer (interlayer time) for different sequence and build orientation combinations

\begin{tabular}{llll}
\hline Specimen & Build orientation & Sequence & $\begin{array}{l}\text { Printing time } \\
\text { of single layer } \\
(\mathrm{s})\end{array}$ \\
\hline Type IV & Flat & Parallel & 982 \\
Type IV & Flat & Series & 195 \\
Type V & Flat & Parallel & 330 \\
Type V & Flat & Series & 67.5 \\
Type V & Stand-on & Parallel & 4.75 \\
Type V & Stand-on & Series & 0.79 \\
\hline
\end{tabular}

Reported interlayer time for stand-on orientation is associated with the printing path in the gauge region

Note: Estimated from Simplify 3D software version 4.1.2
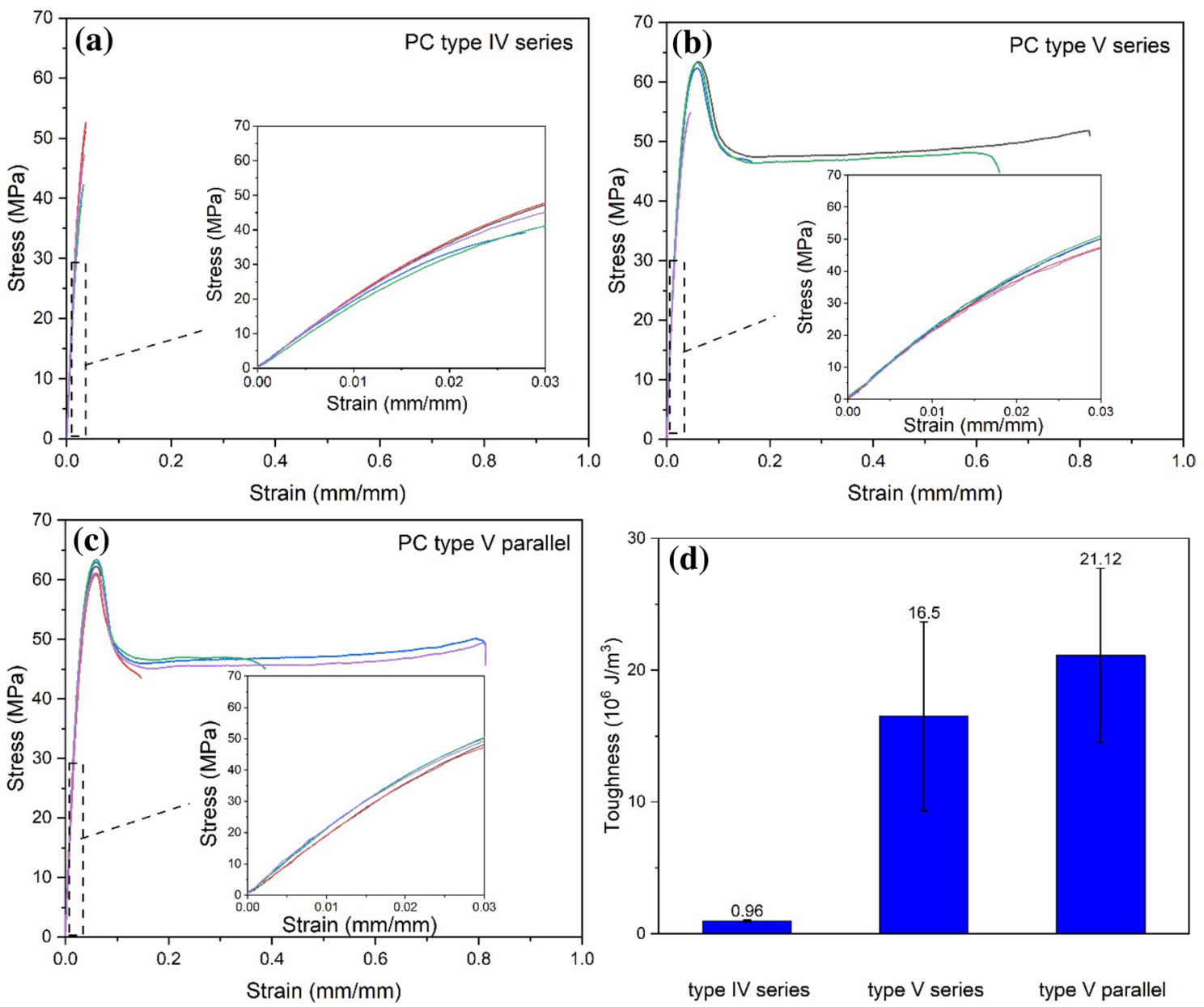

Fig. 2 Stress-strain response of PC tensile bars printed in flat orientation with alternating $0^{\circ} / 90^{\circ}$ raster angle using a Type IV in series, b Type V in series and c Type V in parallel. The different color lines correspond to individual specimens to illustrate the variance in the mechanical response of these printed parts. All type V samples exhib-

ited ductile-like failure, while type IV samples showed brittle failure. d Toughness assessed from the area under the stress-strain curve depends strongly on the size of the PC tensile bar. The error bars represent the standard error $\left( \pm \frac{\alpha}{\sqrt{n}}\right)$ associated with the five printed specimens for each case 
history between layers (see Table 1). As an aside, thermal annealing post processing of the type IV specimens does not produce ductility approaching that of the type V specimens (additional information provided in SI). Despite the significant differences in the stress-strain behavior of type IV and type $\mathrm{V}$ specimens, the elastic modulus of the printed PC is approximately $1.8 \mathrm{GPa}$, irrespective of the print history. A prior comparison of type I and type IV printed PLA indicated that the optimized ultimate tensile strength (UTS) was not significantly influenced by the selection, but the type IV geometry tends to produce higher UTS over the full print parameter space [48]. Examination of the stress at failure indicates a slightly larger UTS with the type V geometry, which is consistent with the prior comparison with PLA in terms of the specimen size effect. Yielding for the specimen printed with the type $\mathrm{V}$ geometry significantly increases the toughness of the printed PC (Fig. 2d). Toughness is more sensitive to the appearance of the tensile curves than elastic modulus or UTS, which are more common metrics to quantify the properties of printed plastics.

To assess the universality of this behavior, a semi-crystalline polymer, PP, was printed using the same geometries and print paths. Unlike PC, PP consistently exhibited ductile failure (Fig. 3a-c) with strain hardening after yielding. This strain hardening is attributed to the extension of tie chains between PP crystals [64]. The elastic modulus and yield stress are both effectively independent of the print details for the three cases examined. However, the type IV specimens tend to fail at slightly lower tensile strains. Figure $3 \mathrm{~d}$ illustrates this difference in terms of the toughness of the printed parts, where the Type IV geometry leads to a lower toughness despite no statistical difference in the elastic modulus
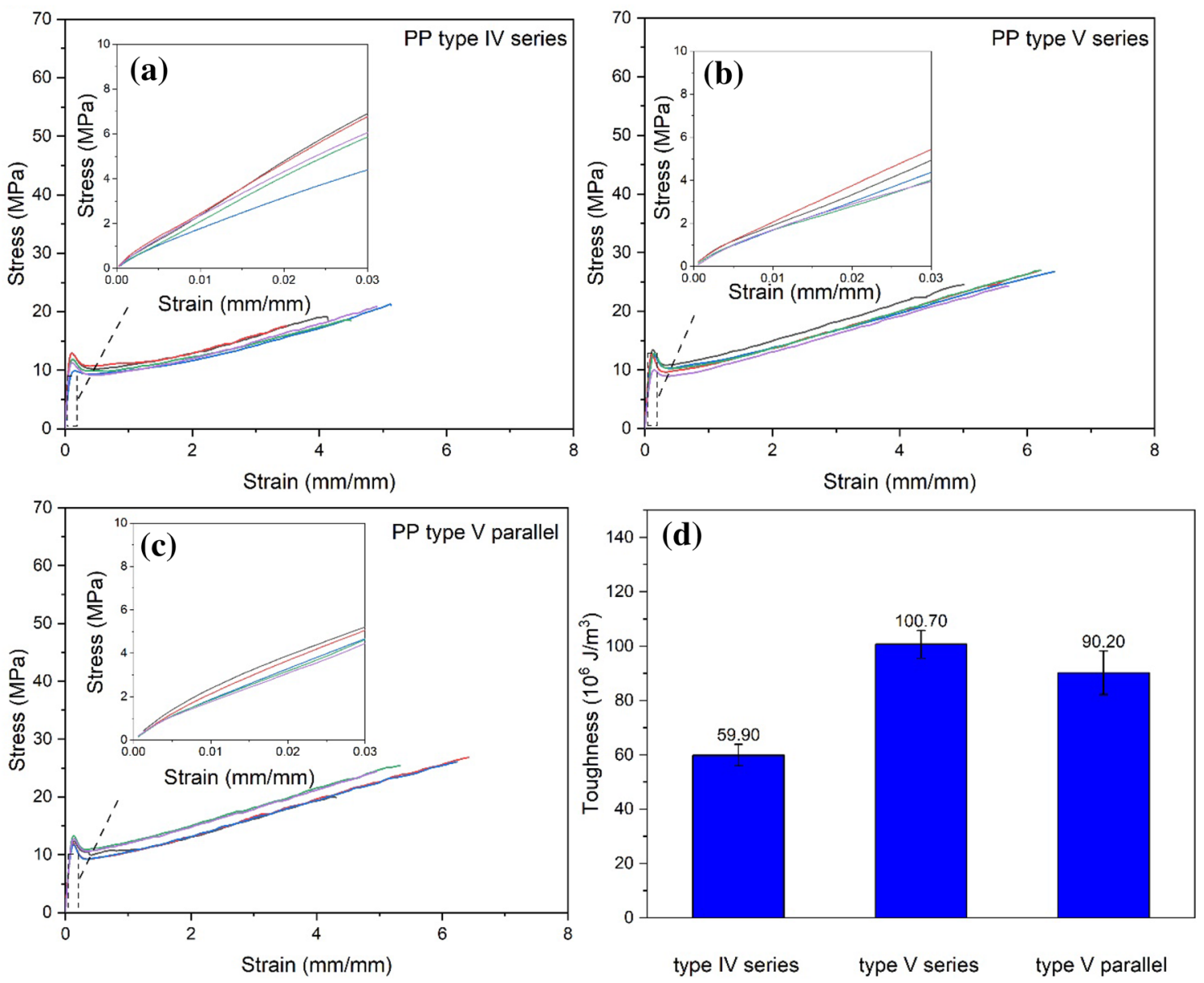

Fig. 3 Stress-strain response of PP tensile bars printed in flat orientation with alternating $0^{\circ} / 90^{\circ}$ raster angle using a Type IV in series, b Type V in series and $\mathbf{c}$ Type $\mathrm{V}$ in parallel. The different color lines correspond to distinct individual specimens printed under the same conditions. All PP tensile bar showed ductile failure. Prior to strain

hardening, all samples exhibit a yield stress. d Toughness of PP tensile bars. All type V samples absorb more energy prior to failure compared with type IV samples. The average of five specimens alone with standard error $\left( \pm \frac{\alpha}{\sqrt{n}}\right)$ 
Table 2 Summary of tensile properties as a function of print conditions with flat $(X Y)$ orientation and alternating $0^{\circ} / 90^{\circ}$ raster angle

\begin{tabular}{|c|c|c|c|c|c|c|}
\hline Polymer & Sequence & Specimen & $\begin{array}{l}\text { Young's modulus } \\
\text { (MPa) }\end{array}$ & Yield stress (MPa) & Toughness $\left(10^{6} \mathrm{~J} / \mathrm{m}^{3}\right)$ & Stress at break (MPa) \\
\hline $\mathrm{PC}$ & Series & Type IV & $1861 \pm 31$ & N/A & $1.0 \pm 0.1$ & $46.5 \pm 2.3$ \\
\hline $\mathrm{PC}$ & Series & Type V & $1891 \pm 16$ & $59.4 \pm 2.0$ & $16.5 \pm 7.2$ & $50.1 \pm 1.7$ \\
\hline $\mathrm{PC}$ & Parallel & Type V & $1819 \pm 35$ & $62.4 \pm 0.3$ & $21.1 \pm 6.6$ & $48.5 \pm 2.9$ \\
\hline $\mathrm{PP}$ & Series & Type IV & $266 \pm 12$ & $11.8 \pm 0.6$ & $59.9 \pm 4.0$ & $18.0 \pm 0.7$ \\
\hline $\mathrm{PP}$ & Series & Type V & $229 \pm 15$ & $12.3 \pm 0.6$ & $100.7 \pm 5.1$ & $25.8 \pm 0.7$ \\
\hline $\mathrm{PP}$ & Parallel & Type V & $243 \pm 10$ & $12.3 \pm 0.1$ & $90.2 \pm 8.0$ & $23.4 \pm 1.4$ \\
\hline
\end{tabular}

Note: Properties reported from five samples for each condition with the mean $(\mu)$ and standard error of mean (SEM) reported

Table 3 Estimated fraction of printed roads with $0^{\circ}$ raster angle in the cross-section of the gauge region (flat orientation)

\begin{tabular}{llll}
\hline Size & Raster angle & $\begin{array}{l}\text { Number of } 0^{\circ} \\
\text { roads in cross- } \\
\text { section }\end{array}$ & $\begin{array}{l}\text { Relative area of gauge } \\
\text { cross-section with } 0^{\circ} \\
\text { roads }(\%)\end{array}$ \\
\hline Type IV & $0^{\circ} / 90^{\circ}$ & 60 & 53.5 \\
Type IV & $0^{\circ}$ & 104 & 92.7 \\
Type IV & $90^{\circ}$ & 16 & 14.3 \\
Type V & $0^{\circ} / 90^{\circ}$ & 36 & 60.6 \\
Type V & $0^{\circ}$ & 56 & 94.2 \\
Type V & $90^{\circ}$ & 16 & 26.9 \\
\hline
\end{tabular}

Note: Calculation based on Simplify 3D software version 4.1.2

with the different tensile geometries. Table 2 summarizes the mechanical properties obtained for the PP and PC as a function of the specimen geometry and print sequence for the flat orientation with alternating $0^{\circ} / 90^{\circ}$ raster angles. The primary differences in properties for the different print conditions are in the toughness and strain to break.

The details of the print path are important to understand these size effects. Some mechanical anisotropy is built into the samples from the build orientation of the printed roads relative to the direction of the applied stress. This internal anisotropy has been reported to be particularly evident for fracture [65]. For the tensile specimens, the thickness, build orientation (flat, XY) and general print conditions are identical, but the width in the gauge region differs by nearly a factor of 2 between Type IV and V specimens. Although the nominal print fill is parallel $\left(0^{\circ}\right)$ for the odd layers and perpendicular $\left(90^{\circ}\right)$ for the even layers, the printed perimeter and turns near the printed perimeter leads to $>50 \%$ parallel roads (see Table 3 ). To test if this difference in the raster angle details is responsible for the different fracture behavior, unidirectional $\left(0^{\circ}\right.$ or $\left.90^{\circ}\right)$ builds were investigated with both geometries. Figure 4a illustrates the ductile failure of Type $\mathrm{V}$ specimens of $\mathrm{PC}$ with the $0^{\circ}$ raster angle. The strain at break was $>0.75$ except one specimen, which is similar to the best performing PC specimens in Fig. 3, but there is a minor decrease in Young's modulus $(1.78 \pm 0.05 \mathrm{GPa})$. Additionally, failure tends to occur near the edge of the gauge region where the width of the print increases (images of all failed specimens are shown in the SI). This locus for the failure is likely associated with defects from the discrete step size associated with the print. Conversely Fig. $4 \mathrm{~b}$ illustrates the stress-strain curves for the Type $\mathrm{V}$ tensile bars printed at $90^{\circ}$ raster angle. These specimens generally exhibited brittle fracture with no yield point, but the brittle failure tended to occur in the clamp region. This tendency for failure in the wider region of the tensile bar can be explained by the difference of intralayer cooling time in between gauge and clamp region, as suggested by Fig. 5, which leads to stronger welds between roads within the gauge region. Nonetheless, the elastic modulus of the PC printed with $90^{\circ}$ raster angle was slightly higher $(1.91 \pm 0.08 \mathrm{GPa})$. Averaging of the elastic modulus for the different build orientations is consistent with the results obtained for the $0^{\circ} / 90^{\circ}$ raster angle shown previously. Figure $4 \mathrm{c}$ shows the stress-strain behavior of Type IV PC specimens with $0^{\circ}$ raster angle. The tensile stress decreases in discrete steps after an apparent yield point. This behavior is associated with intralayer failure of weld lines [66]. The larger specimen size extends the cooling time between adjacent intralayer roads to lead to weaker weld lines for Type IV than Type V specimens with $0^{\circ}$ raster angle. The Type IV PC specimens printed at $90^{\circ}$ raster angle exhibits brittle failure in all cases (Fig. 4d). These differences in the stress-strain behavior with fully oriented roads is consistent changes in the intralayer cooling time based on size and raster angle as summarized in Table 4.

Figure 6 illustrates the fracture surfaces of the printed $\mathrm{PC}$ as a function of the raster angle and the specimen type. The first observation is that there are significant voids in the printed samples, but these voids do not correlate directly with brittle vs. ductile failure. The specimens with the largest strain at break appear to contain more voids (Fig. 6a), 

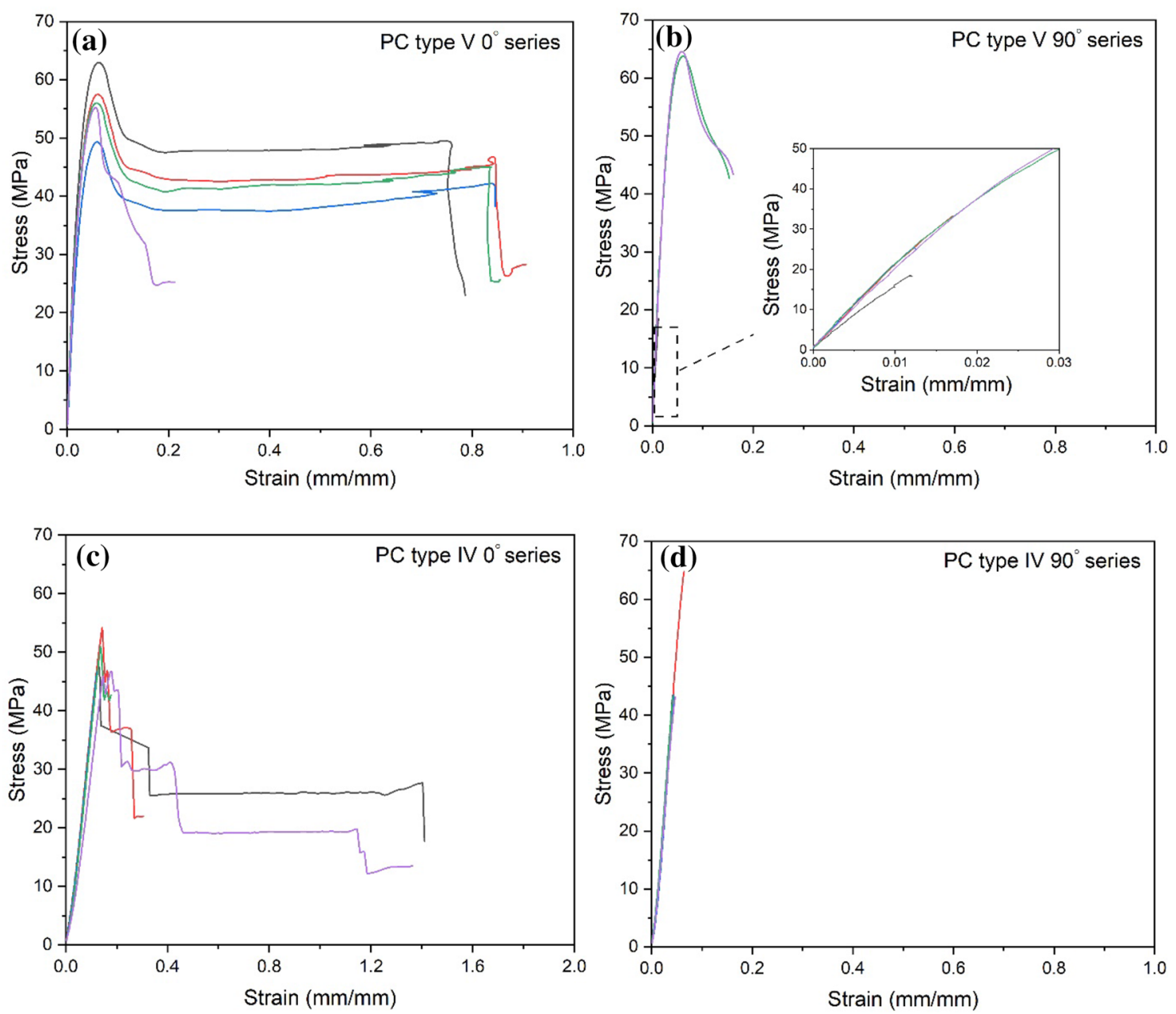

Fig. 4 Stress-strain response of PC when printed at only $\mathbf{a ~} 0^{\circ}$ and $\mathbf{b} 90^{\circ}$ infill with type $\mathrm{V}$ geometry and printed at $\mathbf{c} 0^{\circ}$ and $\mathbf{d} 90^{\circ}$ infill with type IV geometry in flat $(X Y)$ build orientation. For $\mathbf{c}$, the printed lines separate on deformation, which leads to unusual stress-strain response

Type IV $0^{\circ}$ raster angle

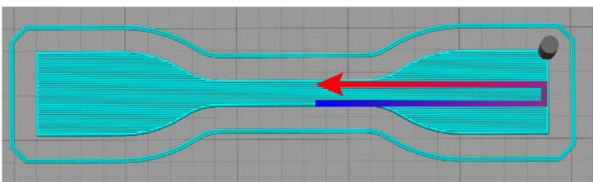

Type $\vee 0^{\circ}$ raster angle

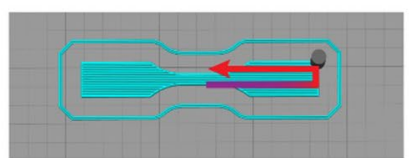

Type IV $90^{\circ}$ raster angle Temperature

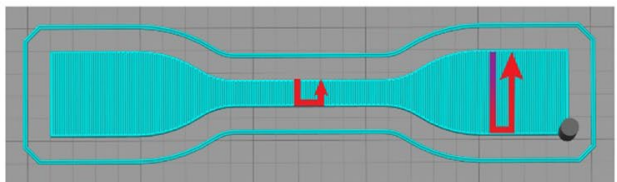

Type $\mathrm{V} 90^{\circ}$ raster angle

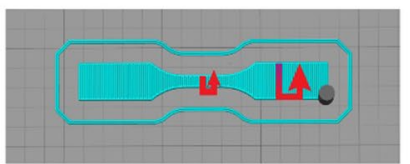

High

Low

Fig. 5 Schematic illustration of expected intralayer thermal history dependence on size of specimen, location, and raster angle for flat build orientation. The maximum high temperature possible is that of the hotend and the minimum low temperature is that of the chamber 
Table 4 Estimated cooling time of intralayer adjacent printed roads within gauge region for different size and raster angle for flat build orientation prints

\begin{tabular}{llll}
\hline Size & Raster angle & $\begin{array}{l}\text { Maximum cooling } \\
\text { time }(\mathrm{s})\end{array}$ & $\begin{array}{l}\text { Minimum } \\
\text { cooling time } \\
(\mathrm{s})\end{array}$ \\
\hline Type IV & $0^{\circ}$ & 5.75 & 4.5 \\
Type IV & $90^{\circ}$ & 0.3 & 0 \\
Type V & $0^{\circ}$ & 3.17 & 2.79 \\
Type V & $90^{\circ}$ & 0.16 & 0 \\
\hline
\end{tabular}

Note: Estimate based on one axis motion only

while the least deformation occurred in the specimen with the least voids visible (Fig. 6d). The fracture surfaces appear rougher for the specimens that exhibited yielding than those that failed at low strain. Specimens that exhibit ductile failure (Fig. 6a, b) contain larger void sizes after failure than samples that exhibit brittle failure. This behavior is likely associated with Poisson's ratio on stretching which narrows the polymer between the voids. These results indicate that large voids are not the primary source for the brittle behavior of $3 \mathrm{D}$ printed plastics at least for the case of $\mathrm{PC}$ under the print conditions examined in this work.

These build orientation effects are significantly suppressed with PP. As shown in Fig. 7a and b, all specimens failed after more than $400 \%$ elongation. This limited effect of the raster angle of the printed roads is consistent with the relatively minor size effect on the full stress-strain behavior when comparing Type IV and V specimens (Fig. 3). The fracture surfaces in Fig. 7 illustrate artifacts from the printed roads are not as prominent in the PP specimens. These micrographs point towards an improved interface between the printed roads as well as improved flow prior to solidification that minimizes voids. This is likely partially attributable to the lower solidification temperature of $\mathrm{PP}\left(88^{\circ} \mathrm{C}\right)$ than PC $\left(143{ }^{\circ} \mathrm{C}\right)$, but more importantly, crystallization across the interface between roads provides a robust mechanical bond without requiring significant diffusion for entanglements as in the case of PC and other glassy polymers [67]. The strength of a weld for glassy polymers depends directly on diffusion and the ability to form entanglements [68]. The lack of entanglements does not impact the mechanical properties of polypropylene significantly due to the effective crosslinking of chains by crystallization [69]. This mechanistic difference means that the conditional requirements for effective welding in 3D printing will be different for glassy and crystalline polymers.

Prior work has demonstrated the importance of interlayer time on the mechanical properties of 3D printed ABS, especially when printed in the stand-on $(Y Z)$ orientation [54]. This result is qualitatively counter to the results reported here. However, the effective time between printed layers will depend on the build orientation and sequence. To shorten the interlayer time, specimens of both PC and PP were printed in the stand-on $(Y Z)$ orientation in both series and parallel. The short interlayer time in the gauge region (see Table 1) leads to good welding between layers, so that the PC printed in series in the stand-on orientation exhibits a similar Young's modulus compared to specimens printed with a flat orientation (Fig. 8a). These specimens are more brittle than those printed with $90^{\circ}$ raster angle only in a flat orientation, which is likely associated with the perimeter in the flat specimens. However, when the stand-on orientation is used in parallel for PC, there is a substantial decrease in the modulus and the
Fig. 6 Tensile fracture surface of PC printed in flat orientation with $\mathbf{a} 0^{\circ}$ and $\mathbf{b} 90^{\circ}$ raster angle with type $\mathrm{V}$ geometry where some yielding was observed and c $0^{\circ}$ and $\mathbf{d ~} 90^{\circ}$ infill with type IV geometry. For $\mathbf{c}$, the fracture propagated along with the road interfaces (parallel to deformation). The white arrow indicates the interlayer direction, while a bracket is used to show the roads associated with the printed perimeter. More details about the raster arrangement are provided SI

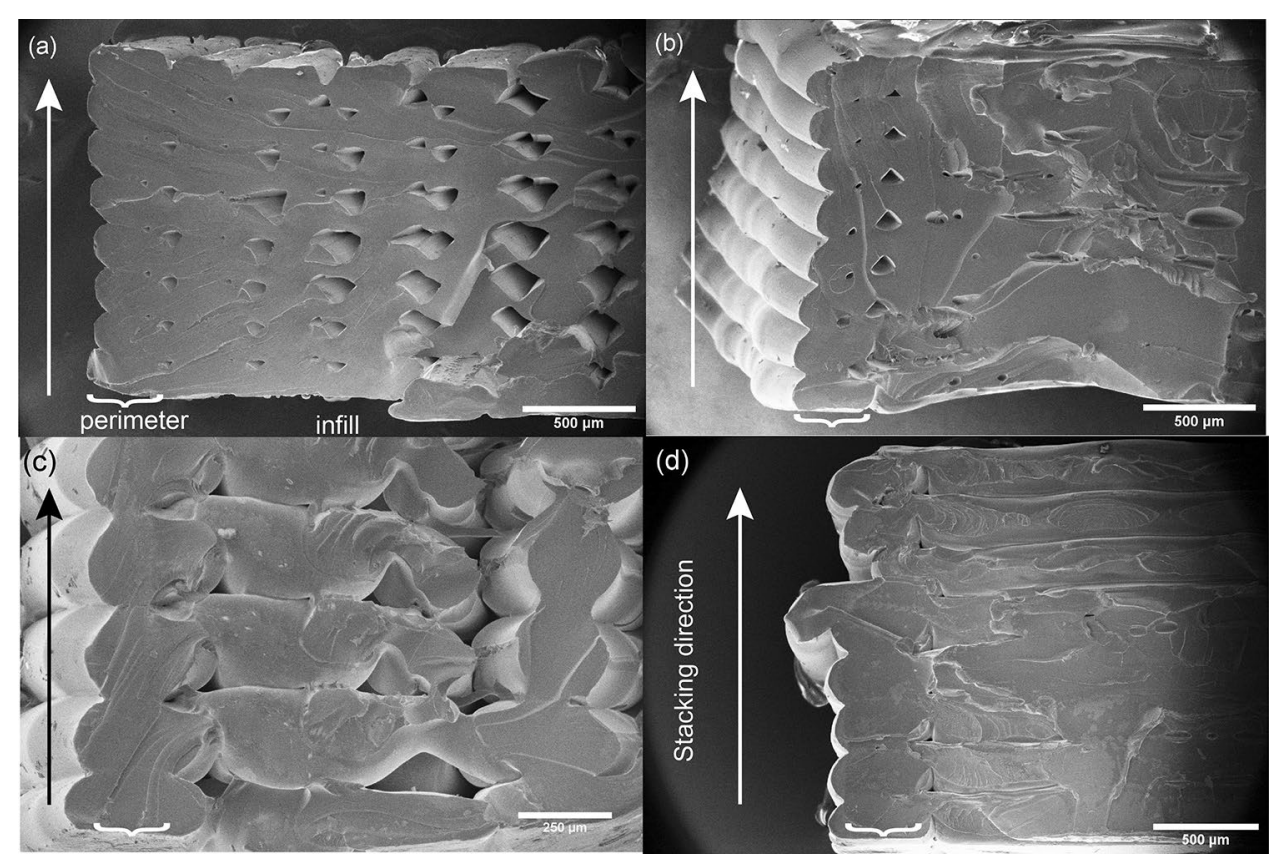



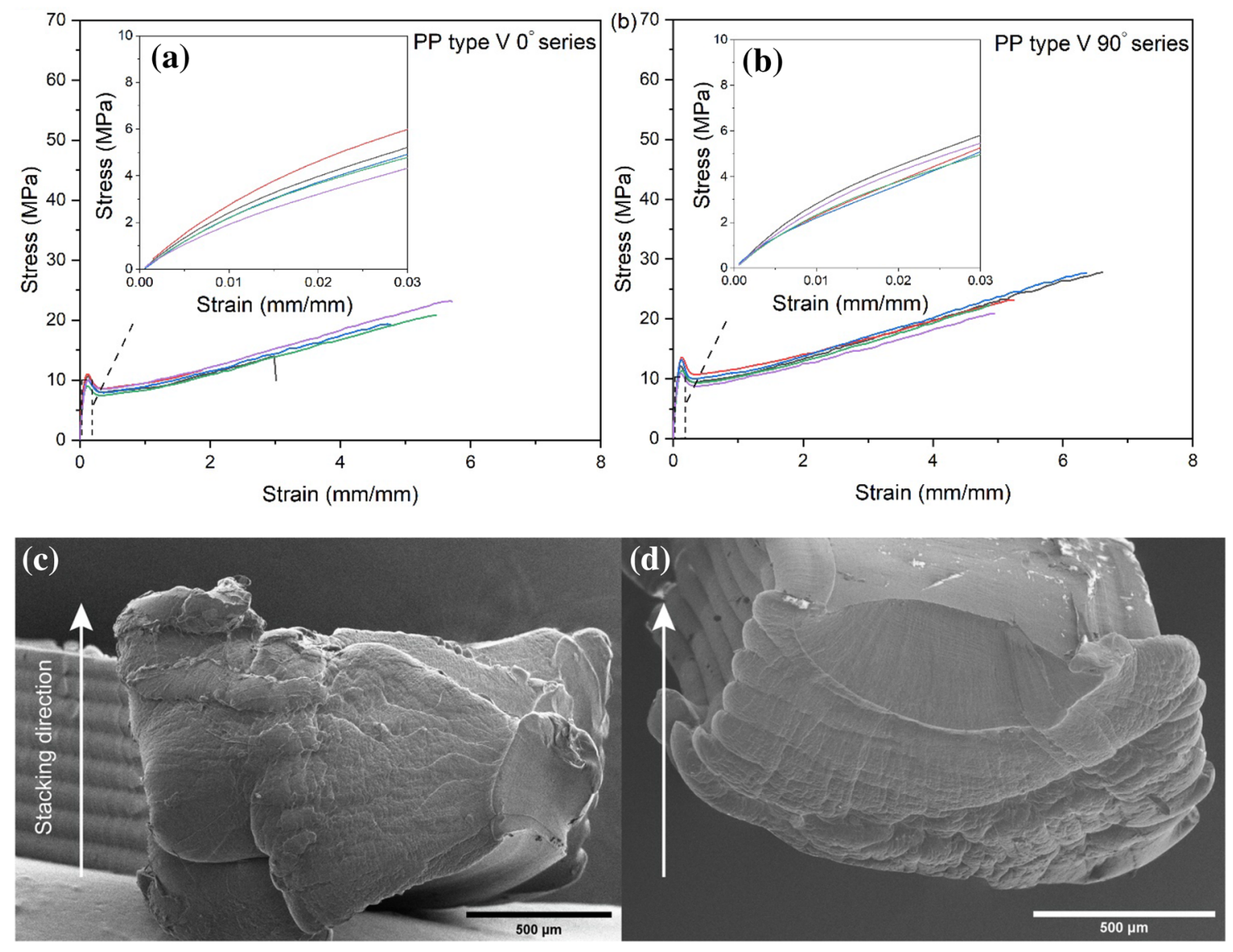

Fig. 7 Stress-strain response of PP when printed at only a $0^{\circ}$ and $\mathbf{b} 90^{\circ}$ infill with type $\mathrm{V}$ geometry. Associated fracture surfaces from SEM based on $\mathbf{c} 0^{\circ}$ and $\mathbf{d ~} 90^{\circ}$ infill. Yielding of the PP during tensile testing obfuscates the interface between the perimeter and primary infill

stress at break is less than one-quarter of the specimens printed in series in stand-on orientation. This behavior is consistent with the change in interlayer time and the time scales where the intralayer (Table 4) time impacts the mechanical response. Similar to the flat orientation, the sequence (series vs. parallel) for printing PP in stand-on orientation does not significantly alter the mechanical response with a small decrease in the strain at break. We attribute this difference in behavior between PC and PP to the reinforcement of crystallites at interfaces between printed roads with PP. Table 5 summarizes the properties of the specimens printed with stand-on orientation. These results suggest that crystallinity leads to decreased sensitivity to the details of the print (size, build orientation, sequence), but crystallization tends to lead to challenges in dimensional accuracy $[8,70]$.

\section{Conclusions}

The process path dependence of the mechanical response of MatEx 3D printed PC and PP was systematically examined. For amorphous PC, the effect of printing multiple samples in parallel was dependent on the build orientation. For the flat orientation, there was no statistical change in the mechanical properties between parallel and series printing but the selection of the test coupon size, which is associated with intralayer cooling time, influenced the specimen failure mechanism. For stand-on orientation, there was a difference in the mechanical performance between parallel and series printing due to the short interlayer time in the gauge region of interest. These effects can be explained in terms of the thermal history of both interlayer and intralayer printed roads that determines the weld strength between roads and can influence the failure mode. The significance of these selections decreases with $\mathrm{PP}$, where there were limited differences in the mechanical response irrespective of sequence, size, and build orientation examined. This insensitivity to processing parameters for PP is attributed to its ability to form strong weld lines through crystallization across printed roads without the diffusion requirements for entanglements which strengthen the glassy PC. The selection of the test coupon has limited impact on the elastic modulus, but influences yielding and 

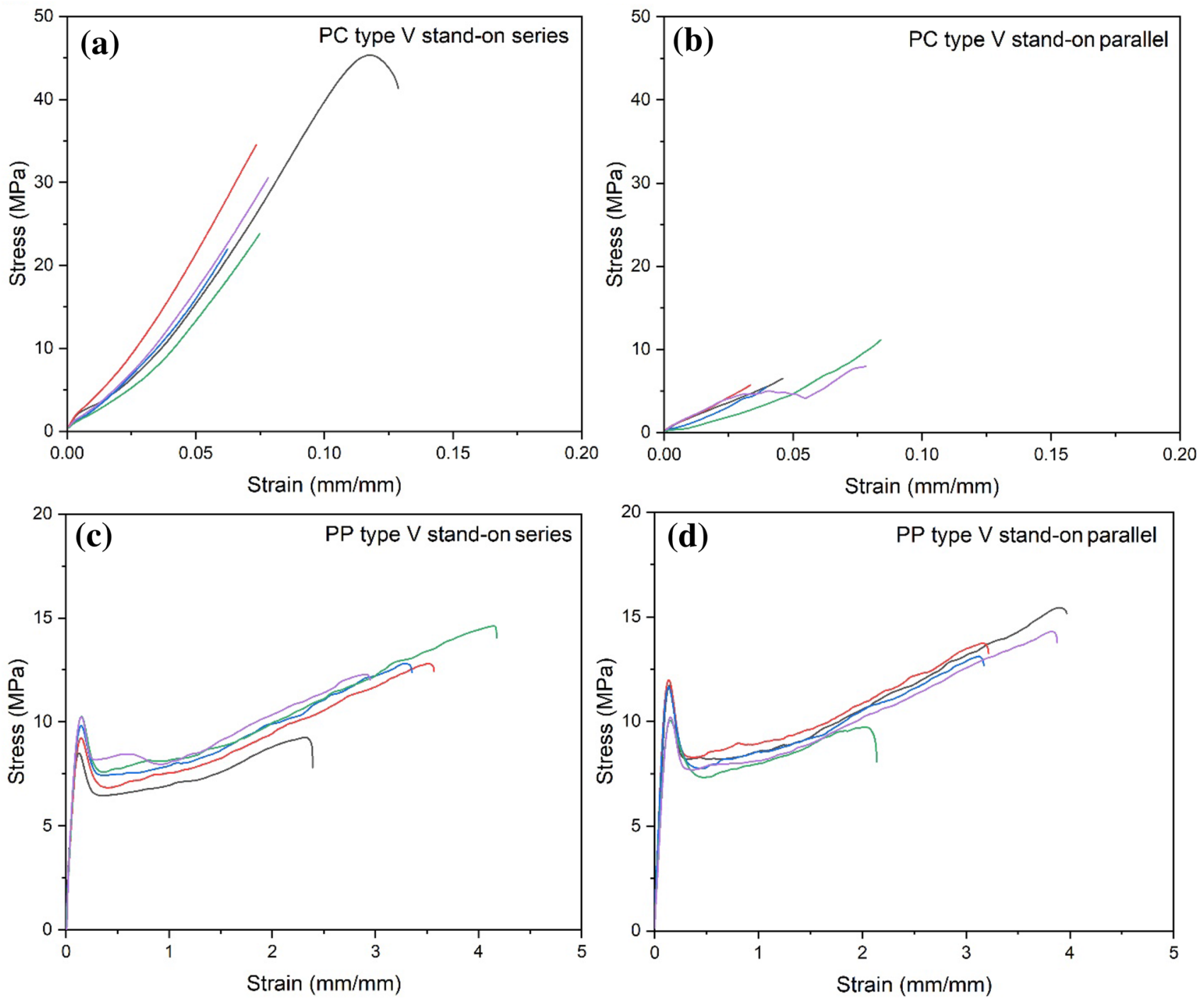

Fig. 8 Stress-strain response of PC printed in a series or $\mathbf{b}$ parallel and PP printed in $\mathbf{c}$ series or $\mathbf{d}$ parallel using stand-on orientation with $0^{\circ} / 90^{\circ}$ raster angle. 5 specimens are shown for each stress-strain curve as indicated by the different color curves

Table 5 Summary of tensile properties of PC and PP with stand-on orientation as a function of print conditions

\begin{tabular}{llllllr}
\hline Polymer & Sequence & Specimen & $\begin{array}{l}\text { Young's modulus } \\
(\mathrm{MPa})\end{array}$ & Yield stress $(\mathrm{MPa})$ & Toughness $\left(10^{6} \mathrm{~J} / \mathrm{m}^{3}\right)$ & Stress at break $(\mathrm{MPa})$ \\
\hline PC & Series & Type V & $1793 \pm 63$ & N/A & $0.7 \pm 0.4$ & $30.4 \pm 3.2$ \\
PC & Parallel & Type V & $1230 \pm 72$ & N/A & $0.02 \pm 0.01$ & $7.4 \pm 0.7$ \\
PP & Series & Type V & $221 \pm 10$ & $9.6 \pm 0.3$ & $51.3 \pm 5.9$ & $11.7 \pm 0.9$ \\
PP & Parallel & Type V & $265 \pm 25$ & $11.1 \pm 0.4$ & $60.6 \pm 5.8$ & $11.4 \pm 1.0$ \\
\hline
\end{tabular}

large strain behavior, so care should be taken in appropriately selecting print coupon size and build orientation for $3 \mathrm{D}$ printed plastics mechanical data use in design. Additionally, these results illustrate that only comparison of elastic modulus of the printed parts does not always provide an accurate representation of the differences in the mechanical response. 
Supplementary Information The online version contains supplementary material available at https://doi.org/10.1007/s40964-022-00275-w.

Acknowledgements This work was financially supported by the National Science Foundation (Grant CMMI-2011298). Polycarbonate materials were supplied by Covestro LLC (Pittsburgh PA).

\section{Declarations}

Conflict of interest On behalf of all authors, the corresponding author states that there is no conflict of interest.

\section{References}

1. Turner BN, Strong R, Gold SA (2014) A review of melt extrusion additive manufacturing processes: I. Process design and modeling. Rapid Prototyp J 20(3):192-204. https://doi.org/10.1108/ rpj-01-2013-0012

2. Booth J, Edwards E, Whitley M, Kranz M, Seif M, Ruffin P (2018) Military comparison of 3D printed Vs commercial components, conference on nano-, bio-, info-tech sensors, and 3D systems II, SPIE-Int Soc Optical Engineering, Denver, CO

3. Thomas-Seale LEJ, Kirkman-Brown JC, Attallah MM, Espino DM, Shepherd DET (2018) The barriers to the progression of additive manufacture: perspectives from UK industry. Int J Prod Econ 198:104-118. https://doi.org/10.1016/j.ijpe.2018.02.003

4. Ligon SC, Liska R, Stampfl J, Gurr M, Mulhaupt R (2017) Polymers for 3D printing and customized additive manufacturing. Chem Rev 117(15):10212-10290. https://doi.org/10.1021/acs. chemrev.7b00074

5. Tareq MS, Rahman T, Hossain M, Dorrington P (2021) Additive manufacturing and the COVID-19 challenges: an in-depth study. J Manuf Syst 60:787-798. https://doi.org/10.1016/j.jmsy.2020. 12.021

6. Ishack S, Lipner SR (2020) Applications of 3D printing technology to address COVID-19-related supply shortages. Am J Med 133(7):771-773. https://doi.org/10.1016/j.amjmed.2020.04.002

7. Spoerk M, Holzer C, Gonzalez-Gutierrez J (2020) Material extrusion-based additive manufacturing of polypropylene: a review on how to improve dimensional inaccuracy and warpage. J Appl Polym Sci 137(12):48545. https://doi.org/10.1002/app. 48545

8. Schirmeister CG, Hees T, Licht EH, Mulhaupt R (2019) 3D printing of high density polyethylene by fused filament fabrication. Addit Manuf 28:152-159. https://doi.org/10.1016/j.addma.2019. 05.003

9. Wu WZ, Geng P, Li GW, Zhao D, Zhang HB, Zhao J (2015) Influence of layer thickness and raster angle on the mechanical properties of 3D-printed PEEK and a comparative mechanical study between PEEK and ABS. Materials 8(9):5834-5846. https:// doi.org/10.3390/ma8095271

10. Cicala G, Ognibene G, Portuesi S, Blanco I, Rapisarda M, Pergolizzi E, Recca G (2018) Comparison of ultem 9085 used in fused deposition modelling (FDM) with polytherimide blends. Materials 11(2):285. https://doi.org/10.3390/ma11020285

11. Bartolai J, Simpson TW, Xie RX (2018) Predicting strength of additively manufactured thermoplastic polymer parts produced using material extrusion. Rapid Prototyp J 24(2):321-332. https:// doi.org/10.1108/rpj-02-2017-0026

12. Patterson AE, Chadha C, Jasiuk IM, Allison JT (2021) Fracture testing of polymer materials processed via fused filament fabrication: a survey of materials, methods, and design applications.
Prog Addit Manuf 6(4):765-780. https://doi.org/10.1007/ s40964-021-00196-0

13. Gao W, Zhang YB, Ramanujan D, Ramani K, Chen Y, Williams CB, Wang CCL, Shin YC, Zhang S, Zavattieri PD (2015) The status, challenges, and future of additive manufacturing in engineering. Comput-Aided Des 69:65-89. https://doi.org/10.1016/j. cad.2015.04.001

14. Camposeco-Negrete C, Varela-Soriano J, Rojas-Carreón JJ (2021) The effects of printing parameters on quality, strength, mass, and processing time of polylactic acid specimens produced by additive manufacturing. Prog Addit Manuf 6(4):821-840. https://doi.org/ 10.1007/s40964-021-00198-y

15. Cicala G, Latteri A, Del Curto B, Lo Russo A, Recca G, Fare S (2017) Engineering thermoplastics for additive manufacturing: a critical perspective with experimental evidence to support functional applications. J Appl Biomater Funct Mater 15(1):E10-E18. https://doi.org/10.5301/jabfm.5000343

16. Vanaei HR, Shirinbayan M, Deligant M, Khelladi S, Tcharkhtchi A (2021) In-process monitoring of temperature evolution during fused filament fabrication: a journey from numerical to experimental approaches. Thermo 1(3):332-360. https://doi.org/10. 3390/thermo 1030021

17. Jin YA, He Y, Xue GH, Fu JZ (2015) A parallel-based path generation method for fused deposition modeling. Int J Adv Manuf Technol 77(5-8):927-937. https://doi.org/10.1007/s00170-014-6530-z

18. Anitha R, Arunachalam S, Radhakrishnan P (2001) Critical parameters influencing the quality of prototypes in fused deposition modelling. J Mater Process Technol 118(1-3):385-388. https://doi.org/10.1016/s0924-0136(01)00980-3

19. Domingo-Espin M, Puigoriol-Forcada JM, Garcia-Granada AA, Lluma J, Borros S, Reyes G (2015) Mechanical property characterization and simulation of fused deposition modeling polycarbonate parts. Mater Des 83:670-677. https://doi.org/10.1016/j. matdes.2015.06.074

20. Ahn SH, Montero M, Odell D, Roundy S, Wright PK (2002) Anisotropic material properties of fused deposition modeling ABS. Rapid Prototyp J 8(4):248-257. https://doi.org/10.1108/13552 540210441166

21. Coogan TJ, Kazmer DO (2020) Prediction of interlayer strength in material extrusion additive manufacturing. Addit Manuf 35:17. https://doi.org/10.1016/j.addma.2020.101368

22. Spoerk M, Arbeiter F, Cajner H, Sapkota J, Holzer C (2017) Parametric optimization of intra- and inter-layer strengths in parts produced by extrusion-based additive manufacturing of poly(lactic acid). J Appl Polym Sci 134(41):45401. https://doi.org/10.1002/ app. 45401

23. Kuznetsov VE, Solonin AN, Tavitov A, Urzhumtsev O, Vakulik A (2020) Increasing strength of FFF three-dimensional printed parts by influencing on temperature-related parameters of the process. Rapid Prototyp J 26(1):107-121. https://doi.org/10.1108/ rpj-01-2019-0017

24. Peng AH, Xiao XM, Yue R (2014) Process parameter optimization for fused deposition modeling using response surface methodology combined with fuzzy inference system. Int J Adv Manuf Technol 73(1-4):87-100. https://doi.org/10.1007/s00170-014-5796-5

25. Goh GD, Yap YL, Tan HKJ, Sing SL, Goh GL, Yeong WY (2020) Process-structure-properties in polymer additive manufacturing via material extrusion: a review. Crit Rev Solid State Mater Sci 45(2):113-133. https://doi.org/10.1080/10408436.2018.1549977

26. Seppala JE, Migler KD (2016) Infrared thermography of welding zones produced by polymer extrusion additive manufacturing. Addit Manuf 12:71-76. https://doi.org/10.1016/j.addma.2016.06. 007

27. Gilmer EL, Anderegg D, Gardner JM, Sauti G, Siochi EJ, McKnight SH, Dillard DA, McIlroy C, Bortner MJ (2021) Temperature, diffusion, and stress modeling in filament extrusion additive 
manufacturing of polyetherimide: An examination of the influence of processing parameters and importance of modeling assumptions. Addit Manuf 48:102412. https://doi.org/10.1016/j.addma. 2021.102412

28. Striemann P, Huelsbusch D, Niedermeier M, Walther F (2021) Application-oriented assessment of the interlayer tensile strength of additively manufactured polymers. Addit Manuf 46:102095. https://doi.org/10.1016/j.addma.2021.102095

29. Seppala JE, Han SH, Hillgartner KE, Davis CS, Migler KB (2017) Weld formation during material extrusion additive manufacturing. Soft Matter 13(38):6761-6769. https://doi.org/10.1039/c7sm0 0950j

30. Matos MA, Rocha A, Costa LA (2020) Many-objective optimization of build part orientation in additive manufacturing. Int J Adv Manuf Technol 112:747-762. https://doi.org/10.1007/ s00170-020-06369-5

31. Murugan RS, Vinodh S (2019) Parametric optimization of fused deposition modelling process using Grey based Taguchi and TOPSIS methods for an automotive component. Rapid Prototyp J 27(1):155-175. https://doi.org/10.1108/rpj-10-2019-0269

32. Garcia-Dominguez A, Claver J, Sebastian MA (2020) Optimization methodology for additive manufacturing of customized parts by fused deposition modeling (FDM). Application to a shoe heel. Polymers 12(9):2119. https://doi.org/10.3390/polym12092119

33. Coogan TJ, Kazmer DO (2019) In-line rheological monitoring of fused deposition modeling. J Rheol 63(1):141-155. https://doi. org/10.1122/1.5054648

34. Anderegg DA, Bryant HA, Ruffin DC, Skrip SM, Fallon JJ, Gilmer EL, Bortner MJ (2019) In-situ monitoring of polymer flow temperature and pressure in extrusion based additive manufacturing. Addit Manuf 26:76-83. https://doi.org/10.1016/j.addma. 2019.01.002

35. Wang X, Zhao LP, Fuh JYH, Lee HP (2019) Effect of porosity on mechanical properties of 3D printed polymers: experiments and micromechanical modeling based on X-ray computed tomography analysis. Polymers 11(7):1154. https://doi.org/10.3390/polym 11071154

36. Hirsch M, Patel R, Li WQ, Guan GY, Leach RK, Sharpies SD, Clare AT (2017) Assessing the capability of in-situ nondestructive analysis during layer based additive manufacture. Addit Manuf 13:135-142. https://doi.org/10.1016/j.addma.2016.10.004

37. Agassant JF, Pigeonneau F, Sardo L, Vincent M (2019) Flow analysis of the polymer spreading during extrusion additive manufacturing. Addit Manuf 29:100794. https://doi.org/10. 1016/j.addma.2019.100794

38. Shmueli Y, Lin YC, Lee S, Zhernenkov M, Tannenbaum R, Marom G, Rafailovich MH (2019) In situ time-resolved X-ray scattering study of isotactic polypropylene in additive manufacturing. ACS Appl Mater Interfaces 11(40):37112-37120. https://doi.org/10.1021/acsami.9b12908

39. Pigeonneau F, Xu D, Vincent M, Agassant JF (2020) Heating and flow computations of an amorphous polymer in the liquefier of a material extrusion 3D printer. Addit Manuf 32:101001. https://doi.org/10.1016/j.addma.2019.101001

40. Peng F, Vogt BD, Cakmak M (2018) Complex flow and temperature history during melt extrusion in material extrusion additive manufacturing. Addit Manuf 22:197-206. https://doi. org/10.1016/j.addma.2018.05.015

41. Costanzo A, Spotorno R, Candal MV, Fernandez MM, Mueller AJ, Graham RS, Cavallo D, McIlroy C (2020) Residual alignment and its effect on weld strength in material-extrusion 3D-printing of polylactic acid. Addit Manuf 36:101415. https:// doi.org/10.1016/j.addma.2020.101415

42. Dunn RM, Hart KR, Wetzel ED (2019) Improving fracture strength of fused filament fabrication parts via thermal annealing in a printed support shell. Prog Addit Manuf 4(3):233-243. https://doi.org/10.1007/s40964-019-00081-x

43. Chohan JS, Mittal N, Kumar R, Singh S, Sharma S, Singh J, Rao KV, Mia M, Pimenov DY, Dwivedi SP (2020) Mechanical strength enhancement of 3D printed acrylonitrile butadiene styrene polymer components using neural network optimization algorithm. Polymers 12(10):2250. https://doi.org/10.3390/ polym 12102250

44. Bakir AA, Atik R, Ozerinc S (2021) Effect of fused deposition modeling process parameters on the mechanical properties of recycled polyethylene terephthalate parts. J Appl Polym Sci 138(3):49709. https://doi.org/10.1002/app.49709

45. El Magri A, El Mabrouk K, Vaudreuil S, Touhami ME (2021) Experimental investigation and optimization of printing parameters of 3 Dprinted polyphenylene sulfide through response surface methodology. J Appl Polym Sci 138(1):49625. https://doi. org/10.1002/app.49625

46. Chaudhry MS, Czekanski A (2020) Evaluating FDM process parameter sensitive mechanical performance of elastomers at various strain rates of loading. Materials 13(14):3202. https:// doi.org/10.3390/ma13143202

47. Garcia-Dominguez A, Claver J, Camacho AM, Sebastian MA (2020) Considerations on the applicability of test methods for mechanical characterization of materials manufactured by FDM. Materials 13(1):28. https://doi.org/10.3390/ma13010028

48. Laureto JJ, Pearce JM (2018) Anisotropic mechanical property variance between ASTM D638-14 type I and type IV fused filament fabricated specimens. Polym Test 68:294-301. https:// doi.org/10.1016/j.polymertesting.2018.04.029

49. Kline DB, Wool RP (1988) Polymer welding relations investigated by a lap shear joint method. Polym Eng Sci 28(1):52-57. https://doi.org/10.1002/pen.760280109

50. Garzon-Hernandez S, Garcia-Gonzalez D, Jérusalem A, Arias A (2020) Design of FDM 3D printed polymers: an experimentalmodelling methodology for the prediction of mechanical properties. Mater Des 188:108414. https://doi.org/10.1016/j.matdes. 2019.108414

51. Deshpande A, Ravi A, Kusel S, Churchwell R, Hsu K (2019) Interlayer thermal history modification for interface strength in fused filament fabricated parts. Prog Addit Manuf 4(1):63-70. https://doi.org/10.1007/s40964-018-0063-1

52. Vega V, Clements J, Lam T, Abad A, Fritz B, Ula N, Es-Said OS (2011) The effect of layer orientation on the mechanical properties and microstructure of a polymer. J Mater Eng Perform 20(6):978 988. https://doi.org/10.1007/s11665-010-9740-z

53. D'Amico T, Peterson AM (2020) Bead parameterization of desktop and room-scale material extrusion additive manufacturing: How print speed and thermal properties affect heat transfer. Addit Manuf 34:101239. https://doi.org/10.1016/j.addma.2020.101239

54. Faes M, Ferraris E, Moens D (2016) Influence of inter-layer cooling time on the quasi-static properties of ABS components produced via fused deposition modelling. Procedia CIRP 42:748753. https://doi.org/10.1016/j.procir.2016.02.313

55. Zaldivar RJ, Witkin DB, McLouth T, Patel DN, Schmitt K, Nokes JP (2017) Influence of processing and orientation print effects on the mechanical and thermal behavior of 3D-Printed ULTEM (R) 9085 Material. Addit Manuf 13:71-80. https://doi.org/10.1016/j. addma.2016.11.007

56. Reich MJ, Woern AL, Tanikella NG, Pearce JM (2019) Mechanical properties and applications of recycled polycarbonate particle material extrusion-based additive manufacturing. Materials 12(10):1642. https://doi.org/10.3390/ma12101642

57. Rohde S, Cantrell J, Jerez A, Kroese C, Damiani D, Gurnani R, DiSandro L, Anton J, Young A, Steinbach D, Ifju P (2018) Experimental characterization of the shear properties of 3D-printed ABS 
and polycarbonate parts. Exp Mech 58(6):871-884. https://doi. org/10.1007/s11340-017-0343-6

58. Stoof D, Pickering K (2018) Sustainable composite fused deposition modelling filament using recycled pre-consumer polypropylene. Compos B 135:110-118. https://doi.org/10.1016/j.compo sitesb.2017.10.005

59. Carneiro OS, Silva AF, Gomes R (2015) Fused deposition modeling with polypropylene. Mater Des 83:768-776. https://doi.org/ 10.1016/j.matdes.2015.06.053

60. Vidakis N, Petousis M, Velidakis E, Spiridaki M, Kechagias JD (2021) Mechanical performance of fused filament fabricated and 3D-printed polycarbonate polymer and polycarbonate/cellulose nanofiber nanocomposites. Fibers 9(11):74. https://doi.org/10. 3390/fib9110074

61. Vidakis N, Petousis M, Velidakis E, Tzounis L, Mountakis N, Kechagias J, Grammatikos S (2021) Optimization of the filler concentration on fused filament fabrication 3D printed polypropylene with titanium dioxide nanocomposites. Materials 14(11):3076. https://doi.org/10.3390/ma14113076

62. Peng F, Zhao ZY, Xia XH, Cakmak M, Vogt BD (2018) Enhanced impact resistance of three-dimensional-printed parts with structured filaments. ACS Appl Mater Interfaces 10(18):16087-16094. https://doi.org/10.1021/acsami.8b00866

63. Dar UA, Xu YJ, Zakir SM, Saeed M-U (2017) The effect of injection molding process parameters on mechanical and fracture behavior of polycarbonate polymer. J Appl Polym Sci 134(7):44474. https://doi.org/10.1002/app.44474

64. Nitta KH, Nomura H (2014) Stress-strain behavior of cold-drawn isotactic polypropylene subjected to various drawn histories. Polymer 55(25):6614-6622. https://doi.org/10.1016/j.polymer.2014. 10.028
65. Allum J, Gleadall A, Silberschmidt VV (2020) Fracture of 3D-printed polymers: crucial role of filament-scale geometric features. Eng Fract Mech 224:106818. https://doi.org/10.1016/j. engfracmech.2019.106818

66. Peng F, Jiang HW, Woods A, Joo P, Amis EJ, Zacharia NS, Vogt BD (2019) 3D printing with core-shell filaments containing high or low density polyethylene shells. ACS Appl Polym Mater 1(2):275-285. https://doi.org/10.1021/acsapm.8b00186

67. Petersmann S, Spoerk-Erdely P, Feuchter M, Wieme T, Arbeiter F, Spoerk M (2020) Process-induced morphological features in material extrusion-based additive manufacturing of polypropylene. Addit Manuf 35:101384. https://doi.org/10.1016/j.addma. 2020.101384

68. Jud K, Kausch HH, Williams JG (1981) Fracture-mechanics studies of crack healing and welding of polymers. J Mater Sci 16(1):204-210. https://doi.org/10.1007/bf00552073

69. Krajenta J, Safandowska M, Pawlak A (2019) The re-entangling of macromolecules in polypropylene. Polymer 175:215-226. https:// doi.org/10.1016/j.polymer.2019.05.015

70. Das A, Marnot AEC, Fallon JJ, Martin SM, Joseph EG, Bortner MJ (2020) Material extrusion-based additive manufacturing with blends of polypropylene and hydrocarbon resins. ACS Appl Polym Mater 2(2):911-921. https://doi.org/10.1021/acsapm. 9b01127

Publisher's Note Springer Nature remains neutral with regard to jurisdictional claims in published maps and institutional affiliations. 